\title{
Prioritizing the Determinants of Social-health Inequality in Iran:A Multiple Attribute Decision Making Application
}

\author{
Rouhollah Zaboli ${ }^{1}$; Sogand Tourani ${ }^{2,}$; Seyed Hesam Seyedin ${ }^{3}$; Alireza Oliaie Manesh ${ }^{4}$ \\ ${ }^{1}$ Department of Health Services Management, School of Health, Baqiyatallah University of Medical Sciences, Tehran, IR Iran \\ ${ }_{2}^{2}$ Hospital Management Research Centre, Iran University of Medical Sciences, Tehran, IR Iran \\ ${ }^{3}$ Health Management and Economics Research Centre, Iran University of Medical Sciences, Tehran, IR Iran \\ ${ }^{4}$ Department of Healthcare Financing and Payment, National Institution of Health Research, Tehran University of Medical Sciences, Tehran, IR Iran \\ ${ }^{*}$ Corresponding Author: Sogand Tourani, Hospital Management Research Centre, Iran University of Medical Sciences, P.O. Box: 1995614111, Tehran, IR Iran. Tel: +98-9122351067, Fax: \\ +98-2188883334, E-mail: r-zaboli@razi.tums.ac.ir
}

Received: June 1, 2013; Revised: June 20, 2013; Accepted: July 8, 2013

\begin{abstract}
Background: One of the main challenges of healthcare systems of developing countries is health inequality. Health inequality means inequality in individuals' ability and proper functioning, resulting in inequality in social status and living conditions, which thwarts social interventions implemented by the government.

Objectives: This study aimed to determine and prioritize the social determinants of health inequality in Iran.

Materials and Methods: This was a mixed method study with two phases of qualitative and quantitative research. The study population consisted of experts dealing with social determinants of health. A purposive, stratified and non-random sampling method was used. Semi-structured interviews were conducted to collect qualitative data along with a multiple attribute decision making method for the quantitative phase of the research in which the TOPSIS technique was employed for prioritization. The qualitative findings were entered into NVivo for analysis, as were the quantitative data entered into MATLAB software.

Results: The results approved the suitability of the conceptual framework of social determinants of health suggested by the WHO (world health organization) for studying social determinants of health inequality; however, this framework general and theoretical rather than a guideline for practice. Thus, in this study, 15 themes and 31 sub-themes were determined as social determinants of social health inequality in Iran. Based on the findings of the quantitative phase of our research, socioeconomic status, living facilities such as housing, and social integrity had the greatest effect on decreasing health inequality.

Conclusions: A major part of the inequality in health distribution is avoidable because they are mostly caused by adjustable factors like economic conditions, educational conditions, employment, living facilities, etc. As in the majority of developing countries the living and health conditions are the same as Iran, the findings of this study may be applicable for other developing countries.
\end{abstract}

Keywords:Social Determinants of Health; Socioeconomic Factors; Iran

\section{Background}

Health is a special goods and its proper distribution should be the main concern of policy makers $(1,2)$. Inequality in health causes inequality in individuals' ability and proper functioning. Such inequality will systematically cause unequal social status and living conditions resulting in the failure of the government's social interventions (3). The concept of equality is a target set for health policies and the concept of health is important and valuable to every individual (4). The international framework for human rights emphasizes on the approach for health justice through concentrating on the social determinants of health. This framework is based on the universal declaration of human rights according to which each individual and their family are entitled to standard living conditions in terms of health and well-being including food, housing, healthcare and social services $(5,6)$.

Today, there is strong scientific evidence for the enormous effect of social indicators such as social class, social deprivation, urban marginality, stress, early childhood development, unemployment, social support, addiction, food, transportation, urbanization, immigration, and globalization, on health (7-10). If the social determinants of health in a society do not receive proper attention, healthcare provision will not significantly enhance individuals' health. As a result, the paradigm that suggests healthcare alone can enhance living conditions has been disparaged $(11,12)$. Scientifically, eradication of healthcare inequality mandates elucidating the relationship between social factors and their effect on health (13). According to the Commission of Social Determinants of Health, health inequality is a toxic combination of social

Implication for health policy/practice/research/medical education:

A major part of the inequality in health is avoidable. Determination of priorities can be considered in policy making and planning to reduce some of them.

Copyright (C) 2014, Iranian Red Crescent Medical Journal; Published by Kowsar Corp. This is an open-access article distributed under the terms of the Creative Commons Attribution License, which permits unrestricted use, distribution, and reproduction in any medium, provided the original work is properly cited. 
Zaboli Ret al.

policies, plans, unjust economical arrangements, and wrong policy making (14-16). One of the models used to study inequality in health was first introduced by the Netherlands. This model suggests the following measures should be taken regarding policy making for social determinants of health policies: reducing the unequal distribution of socioeconomic factors or structural variables, effective control of intermediary determinants of socioeconomic factors, control of reverse effects of health on socioeconomic status and finally concerns about curative healthcare services in curative healthcare systems (17). Social factors determine health-relevant behaviors and health consequences. Effective health interventions require community-oriented approaches as the determinants of social health approach (18). From the early 1990 s to 2000 , social determinants of health were considered as the main concern of countries, but evidence shows that the social measures taken by these countries, particularly developing countries, to decrease the inequality and promote health justice were not successful (19-22). In order to decrease health inequality, countries have taken different actions. The British health inequality decrease plan based on social factors, the Swedish determinantsoriented national public health strategy, free market economy, Neo-liberalism and community-oriented medicine in the developing countries of the Latin Americas, East Mediterranean, Asian and African regions, all looked for the social roots of illnesses $(10,23-27)$.

Commission on Social Determinants of Health was founded in 2003 to study health justice. Lee (2005) believed that countries' health interventions aimed at tackling diseases and saving lives failed and were not able to decrease inequality and injustice. The 2008 report of this commission encouraged action against health inequality in different countries to fill the gaps between socioeconomic and political factors through research about and identification of social determinants of health (28-31). Commitment to health justice requires a healthgradients approach in which not only the cause of inequality is studied but also the differences in lifestyles and living standards among different socioeconomic groups are accounted (32-35). Despite the 20th century improvements in the global general health, health inequality has increased and evidence shows that in order to prevent health inequality, social determinants of health should be attended to. Countries should attempt to reduce health inequality by paying attention to social determinants of health (36-39). The coordination of the health sector with other relevant sectors provides an optimal opportunity but there are numerous challenges and inconveniences. Iran's health care system regarding demographic factors, health status indicators such as responsiveness and health equity is not appropriate when compared to developed countries and some Middle East countries. Despite the improvement in health status during the past 30 years, health inequalities have produced various problems in our country. Resource decentraliza- tion, serious problems of efficiency, quality of care, lack of access to minimum basic needs, and other social determinants; social determinants of health approach is needed. Based on the conceptual framework of social determinants of health inequality, this research used the multiple attribute decision-making method by considering the local development conditions of the country and priorities for policy making.

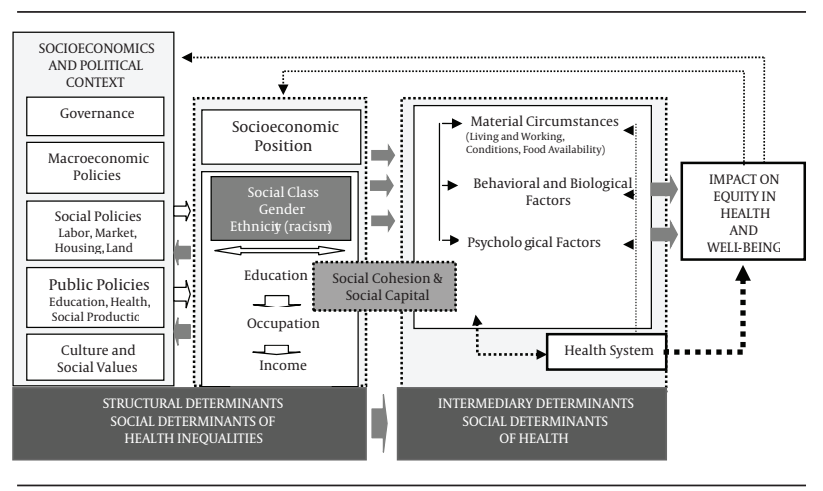

Figure 1. Final Form of the CSDH Conceptual Framework (40)

\section{Objectives}

This study aimed to determine and prioritize the social determinants of health inequality in Iran.

\section{Material and Methods}

This study was a mixed method research conducted in two phases:

\subsection{Phase 1: Qualitative Phase}

In this phase, the study population consisted of experts in social determinants of health. The inclusion criteria were as follows: being an expert with a minimum of three years experience, holding a PhD degree in health management \& policy, clinical and social sciences and related specialties. Purposive non-random stratified sampling was used. Tashakkori and Teddlie reported that with this sampling method, the cases were purposively and non-randomly selected (41). Maximum variation sampling was used for data collection. It was estimated that the sample size of this study would be 40 experts. We also used semi-structured interviews to collect qualitative data. This guideline was made of a number of main questions regarding social determinants of health. We did not carry out the literature review with a setting of social determinants because our conceptual framework was based on the World Health Organization; this is indicated in Figure 1. Before interviewing, a pilot interview was conducted on a small scale. Interviews were continued to the point of data saturation. The number of participants in this study was 24 experts. Data were collected from experts during the period between December 2012 and April 2013 in the city of Tehran, Iran. 
After the interviews were over, they were transcribed and a version of the transcription was sent to the interviewee for confirmation. Framework analysis was used next and then thematic analysis was implemented with Nvivo to determine the main themes and sub-themes. According to the framework analysis these steps were conducted: 1) familiarization, 2) identification of a thematic framework, 3) indexing, 4) charting and 5) mapping and interpretation. The coding of the manuscripts was guided by a primary coding frame derived from the conceptual framework of social determinants of health also research questions. Within this, new codes were developed, searching both for key concepts and for passages aimed at illustrating specific themes and sub-themes. The main social determinants of health inequalities were extracted in the qualitative phase while in the quantitative phase they were prioritized.

\subsection{Phase 2: Multiple Attribute Decision Making Analysis Via TOPSIS}

There are various models to rank and prioritize the measures taken by different researches; the most well known among models is the family of multiple attribute decision making which uses techniques such as the technique for order of preference by similarity to ideal solution (TOPSIS) which are widely used in a variety of science disciplines due to their practicality. The multiple attribute decision making approach was selected as the data collection method for the quantitative phase. By the TOPSIS technique, the criteria were weighted and chosen in accordance with qualitative studies and the experts' knowledge. TOPSIS was introduced by Hong-Lee and Lei. TOPSIS was selected as one of the compensatory classic methods in multiple attribute decision making to solve the problems of prioritization based on similarity to ideal solution $(42,43)$. The TOPSIS method, a multiple attribute decision-making (MADM) technique, was used to perform the prioritization in this study. The SAW method is exploited to identify the weights of each factor. The experts could use the following nine-points for expressing the intensity of the preference for one criterion versus another:

$1=$ Equal importance or preference.

3 = Moderate importance or preference of one over another.

$5=$ Strong or essential importance or preference.

7 = Very strong or demonstrated importance or preference.

$9=$ Extreme importance or preference.

The TOPSIS technique consists of the following steps (43):

1. Compute the normalized decision matrix. The normalized value $r_{i j}$ is calculated as (Equation 1):
Equation 1.

$$
r_{i j}=\frac{f_{i j}}{\sqrt{\sum_{j}^{J} f^{2}}}
$$

$\mathrm{J}=1, \mathrm{~J} ; \mathrm{i}=1, \mathrm{n}$

2. Calculate the weighted normalized decision matrix. The weighted normalized value vij is calculated as:

$\mathrm{V}_{\mathrm{ij}}=\mathrm{w}_{\mathrm{i}} \mathrm{r}_{\mathrm{ij}}$

$\mathrm{j}=1, \mathrm{~J} ; \mathrm{I}=1, \mathrm{n}$

Where $w_{i}$ is the weight of the ith attribute or criterion, and (Equation 2)

Equation 2. $\quad \sum_{i=1}^{n} w_{i}=1$

3. Determine the ideal and negative-ideal solution (Equations 3 and 4).

Equation 3.

$\mathrm{A}^{+}=\left\{\mathrm{V}_{\mathrm{i}}^{+}, \ldots \mathrm{V}_{\mathrm{n}}^{+}\right\}=\left\{\left(\max \mathrm{V}_{\mathrm{ij}} \mid \mathrm{i} \in \mathrm{I}^{\prime \prime}\right),\left(\min \mathrm{V}_{\mathrm{ij}} \mid \mathrm{i} \in \mathrm{I}^{\prime \prime}\right)\right\}$

Equation 4.

$\mathrm{A}^{-}=\left\{\mathrm{V}_{\mathrm{i}}^{-}, \ldots \mathrm{V}_{\mathrm{n}}^{-}\right\}=\left\{\left(\min \mathrm{Vij} \mid \mathrm{i} \in \mathrm{I}^{\prime}\right),\left(\max \mathrm{V}_{\mathrm{ij}} \mid \mathrm{i} \in \mathrm{I}^{\prime \prime}\right)\right\}$

Where I' is associated with advantage criteria and I" is associated with cost criteria.

4. Calculate the separation measures, using the n-dimensional Euclidean distance. The separation of each alternative from the ideal solution is given as (Equation 5):

Equation 5. $\quad D_{j}^{+}=\sqrt{\sum_{i=1}^{n}\left(v_{i j}-v_{i}^{+}\right)^{2}}$

$\mathrm{j}=1, \mathrm{~J}$

Similarly, the separation from the negative-ideal solution is given as (Equation 6):

Equation 6. $D_{j}^{-}=\sqrt{\sum_{i=1}^{n}\left(v_{i j}-v_{i}^{-}\right)^{2}}$

$\mathrm{j}=1, \mathrm{~J}$

5. Calculate the relative closeness to the ideal solution. The relative closeness of the alternative aj with respect to $\mathrm{A}^{*}$ is defined as (Equation 7):

Equation 7.

$$
C_{j}^{+}=\frac{D_{j}^{-}}{D_{j}^{+}+D_{j}^{-}}
$$

$$
\mathrm{j}=1, \mathrm{~J}
$$


6. Rank the preference order.

The whole process was performed by the MATLAB software.

\section{Results}

In this study, 50\% of interviewees were male, eight of the 24 interviewed had studied health management and policy, and seven were clinicians, three of the 24 interviewed had studied social sciences and eight had studied a related specialty. $75 \%$ of the experts (18 of the 24 ) were found to hold 15 years of experience or above. We found that the conceptual framework of social determinants of health presented by WHO was a proper model for studies on the aspects of social determinants of health and health inequality. Also, it was proved to be more of a general model and more theoretical than practical. In this study, 15 themes and 43 subthemes emerged as the social determinants of health and inequality in Iran. As mentioned earlier, socioeconomic position, living facilities such as housing and social integrity have the strongest influence on decreasing health inequality according to expert opinion in Iran (Table 1).

\section{Discussion}

A major part of health inequality is preventable and can be decreased because it has roots in adjustable factors. Such factors may include economic status; education levels; employment and living facilities. In fact, health justice indicates that under ideal conditions, everybody has a fair opportunity to enjoy complete physical, psychological, spiritual and social health and no one should be deprived of reaching such opportunities. Economic position is one of the most important and influential determinants of health and well-being, especially in developing countries. This determinant plays its role through influencing other factors like healthcare availability, healthy nutrition, education, and housing. However, the relationship between these two variables is bilateral and a healthy population means less poverty and greater economical growth. Therefore, all political models and governmental plans focus on promoting incomes and its better distribution; in other words, they concentrate on economic justice.

\begin{tabular}{|c|c|c|c|}
\hline Name & Sex & Subject Area Studied & Work Experience \\
\hline Expert \#1 & male & $\begin{array}{l}\text { health management \& policy } \\
\text { (HMP) }\end{array}$ & $<15$ years \\
\hline Expert \#2 & female & $\operatorname{clinical}(\mathrm{C})$ & $>15$ years \\
\hline Expert \#3 & female & other specialty (OS) & $<15$ years \\
\hline Expert \#4 & female & health management \& policy & $<15$ years \\
\hline Expert \#5 & female & clinical & $<15$ years \\
\hline Expert \#6 & male & clinical & $<15$ years \\
\hline Expert \#7 & male & health management \& policy & $<15$ years \\
\hline Expert \#8 & female & clinical & $>15$ years \\
\hline Expert \#9 & male & other specialty & $<15$ years \\
\hline Expert \#10 & female & other specialty & $<15$ years \\
\hline Expert \#11 & female & clinical & $<15$ years \\
\hline Expert \#12 & male & other specialty & $<15$ years \\
\hline Expert \#13 & female & clinical & $>15$ years \\
\hline Expert \#14 & male & clinical & $<15$ years \\
\hline Expert \#15 & male & other specialty & $>15$ years \\
\hline Expert \#16 & male & health management \& policy & $<15$ years \\
\hline Expert \#17 & female & social science (SS) & $<15$ years \\
\hline Expert \#18 & male & social science & $>15$ years \\
\hline Expert \#19 & male & social science & $>15$ years \\
\hline Expert \#20 & male & other specialty & $<15$ years \\
\hline Expert \#21 & female & health management \& policy & $<15$ years \\
\hline Expert \#22 & male & health management \& policy & $<15$ years \\
\hline Expert \#23 & male & other specialty & $<15$ years \\
\hline Expert \#24 & male & other specialty & $<15$ years \\
\hline
\end{tabular}

$\mathrm{a}_{\text {Totals: }} 14$ male; 14 female; $\mathrm{HMP}=6 ; \mathrm{C}=7 ; \mathrm{SS}=3 ; \mathrm{OS}=8 ;<15$ years $=18 ;>15$ years $=6$. 
Table 2. Social Determinants of Health Inequality in Iran Based on Expert Opinion

\begin{tabular}{ll}
\hline Themes & Sub-themes \\
\hline Disaster and crisis & vulnerable group; road accidents \\
\hline Socioeconomic position & income; social class \\
\hline Public policies & health policy; organizational commitment; multi disciplinary participation \\
\hline Material circumstances & food availability; living conditions and facilities; nutrition of target populations \\
\hline Education & health literacy; education levels; people empowerments and capability \\
\hline Social policies & labor and employment; marginalization and immigration; housing \\
\hline Culture and religious & religious principles and faith; social and individual behavior \\
\hline Life style & sexual behavior; life skills; health skills and drug abuse; risk factors \\
\hline Macroeconomic policies & public and private policies; health policy; out-of pocket \\
\hline Early childhood development & micronutrient deficiency; childhood care \\
\hline Social protection & comprehensive social security; insurance \\
\hline Health care system & phc; financial; physical and technological access; media access \\
\hline Behavioral and biological factor & cultural factor; rudeness; environment \\
\hline Social cohesion and social capital & ngos; social capital; social network; multi disciplinary participation \\
\hline Ethnicity & gender; gender lens \\
\hline International factor & international sanctions and boycotts; health diplomacy \\
\hline
\end{tabular}

Table 3. Prioritizing the Social Determinants of Health Inequality in Iran by the TOPSIS Technique

\begin{tabular}{|c|c|c|c|c|}
\hline $\begin{array}{l}\text { Social Determinants } \\
\text { of Health Inequality }\end{array}$ & $\begin{array}{c}\text { Separation From the } \\
\text { positive-ideal Solu- } \\
\text { tion } D^{+}{ }_{j}\end{array}$ & $\begin{array}{c}\text { Separation From the } \\
\text { Negative-ideal Solu- } \\
\text { tion } D_{j}^{-}\end{array}$ & 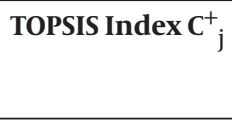 & $\begin{array}{c}\text { Rank the Preference } \\
\text { Order }\end{array}$ \\
\hline $\begin{array}{l}\text { Socioeconomic posi- } \\
\text { tion }\end{array}$ & 0.0283 & 0.0591 & 0.6762 & 1 \\
\hline Social policies & 0.0332 & 0.0675 & 0.6703 & 2 \\
\hline $\begin{array}{l}\text { Social cohesion and } \\
\text { social capital }\end{array}$ & 0.0236 & 0.0478 & 0.6694 & 3 \\
\hline $\begin{array}{l}\text { Macroeconomic poli- } \\
\text { cies }\end{array}$ & 0.0287 & 0.0513 & 0.6413 & 4 \\
\hline Culture and religious & 0.0315 & 0.0563 & 0.6412 & 5 \\
\hline Public policies & 0.0280 & 0.0499 & 0.6405 & 6 \\
\hline Social protection & 0.0311 & 0.0484 & 0.6088 & 7 \\
\hline $\begin{array}{l}\text { Early childhood devel- } \\
\text { opment }\end{array}$ & 0.0315 & 0.0458 & 0.5924 & 8 \\
\hline Life style & 0.0327 & 0.0471 & 0.5902 & 9 \\
\hline Health care system & 0.0371 & 0.0513 & 0.5803 & 10 \\
\hline International factors & 0.0348 & 0.0472 & 0.5756 & 11 \\
\hline Disaster and crisis & 0.0366 & 0.0494 & 0.5744 & 12 \\
\hline $\begin{array}{l}\text { Behavioral and bio- } \\
\text { logical factors }\end{array}$ & 0.0355 & 0.0437 & 0.5517 & 13 \\
\hline Education & 0.0354 & 0.0430 & 0.5484 & 14 \\
\hline Ethnicity & 0.0363 & 0.0412 & 0.5316 & 15 \\
\hline
\end{tabular}


Employment, psychological and social support, urban and rural residence, socioeconomic factors and social status, and culture are the most important determinants of health inequality in developing countries $(14,18,44$ 51). Moreover, the attainment of healthcare facilities in different provinces is one of the major causes of health inequality in Iran (52).

Health inequality is a special case of difference in health, where the groups that are socially vulnerable or in permanent improper and discriminative social conditions systematically suffer from severer health conditions, and are at higher risks compared to the groups enjoying an optimal social status (19). Socioeconomic inequalities and their effects on health are one of the challenges that have recently attracted attention because improving health in afflicted societies is more difficult than helping patients in a healthy society. The majority of factors causing health inequality are distributed all over different social sectors. Therefore, it is necessary to take a multidisciplinary approach in policy-making and to evaluate the probable effects of policies on health, particularly on the health of the most vulnerable groups of the society. However, the notion of health does not extend far beyond medical care to the policy makers of some developing countries and as a result; they are not able to understand the close relationship between health and their own duties. The health sector is held responsible for informing the policy-makers of such matters.

To investigate the main roots of factors threatening health, the causes of inequality should be recognized and then, serious measures must be taken to correct them through public cooperation (11). This research also determined social integrity as one of the most important and highly prioritized determinants of health inequality. There are social issues such as poverty, unemployment, and illiteracy in each country to different extents. It is important to know that the effect of each variable on health distribution is determined first by its partial effect and second by its effect on socioeconomic distribution; they interact and have a synergetic outcome (53). The concept of justice is among basic religious concepts. Unequal opportunities can affect the health of the economy, society and families, in addition to the social and psychological health of individuals. Unequal distribution of income, employment, education, and facilities plus social class inequalities in terms of skin color, race, and nationality can lower health indices. In this research, these factors were also identified. Regarding the social determinants of health, the majority of health provision is warranted out of the health sector. Education, housing, urban planning, and welfare are the sectors with a considerably large share in health. In order to decrease inequality, new paradigms should be developed through combination of science, practice and politics $(24,32,54)$. Considering the current unequal policies, restricted resources, lack of a comprehensive approach, and lack of a health approach, the determinants were prioritized. This study had some potential limitations that may affect the results. Lack of a comprehensive understanding about the social determinants of health was found as the most important limitation.

A major part of the inequality in health distribution is avoidable because they are mostly caused by adjustable factors such as economic conditions, education conditions, employment, living facilities, etc. Finally, this study was conducted with respect to Iran while there are lessons for health organizations in developing countries specially countries in the Middle East. These findings can be considered for policy making and resource distribution.

\section{Acknowledgements}

There is no acknowledgment.

\section{Author's Contribution}

Study concept and design: Sogand Tourani, Rouhollah Zaboli and Seyed Hesam Seyedin; analysis and interpretation of qualitative data: Rouhollah Zaboli, Seyed Hesam Seyedin, and Alireza Oliaie Manesh; statistical analysis and interpretation of quantitative data: Rouhollah Zaboli, and Sogand Tourani; drafting of the manuscript: Rouhollah Zaboli and Seyed Hesam Seyedin; critical revision of the manuscript: Sogand Tourani, Seyed Hesam Seyedin and Alireza Oliaie Manesh.

\section{Financial Disclosure}

There is no financial disclosure.

\section{Funding/Support}

This study was part of a project supported by the Iran University of Medical Sciences (IUMS/SHMIS-2011/627).

\section{References}

1. Anand S, Hanson K. DALYs: efficiency versus equity. World Dev. 1998;26(2):307-10.

2. Anand S, Sen A. Human Development and Economic Sustainability. World Dev. 2000;28(12):2029-49.

3. Boot M. The Aim of a Theory of Justice. Ethical Theory Moral Pract. 2012;15(1):7-21.

4. Ruger JP. Health, capability, and justice: toward a new paradigm of health ethics, policy and law. Cornell J Law Public Policy. 2006;15(2):403-82

5. Gruskin S, Tarantola D. Health and Human Rights: Overview. In: Heggenhougen HK editor. International Encyclopedia of Public Health.. Oxford: Academic Press; 2008. pp. 137-46.

6. Tarantola D, Gruskin S. Human Rights Approach to Public Health Policy. In: Heggenhougen HK editor. International Encyclopedia of Public Health.. Oxford:Academic Press; 2008. pp. 477-86.

7. Solar O, Irwin A. Social determinants, political contexts and civil society action: a historical perspective on the Commission on Social Determinants of Health. Health Promot J Austr. 2006;17(3):180.

8. Watt RG. Social determinants of oral health inequalities: implications for action. Community Dent Oral Epidemiol. 2012;40 Suppl 2:44-8.

9. Irwin A, Solar O, Vega J. Social Determinants of Health, the Unit- 
Zaboli Ret al.

ed Nations Commission of. In: Heggenhougen HK editor. International Encyclopedia of Public Health.. Oxford: Academic Press; 2008. pp. 64-9.

10. Graham H. Social determinants and their unequal distribution: clarifying policy understandings. Milbank Q. 2004;82(1):101-24.

11. Anderko L. Achieving health equity on a global scale through a community-based, public health framework for action. J Law Med Ethics. 2010;38(3):486-9.

12. Daniels N. Just health: replies and further thoughts. J Med Ethics. 2009;35(1):36-41.

13. Griffith DM, Johnson J, Ellis KR, Schulz AJ. Cultural context and a critical approach to eliminating health disparities. Ethn Dis. 2010;20(1):71-6.

14. Llorca I Ibanez E. Municipality, space and the social determinants of health. Environ Urban. 2011;23(1):113-7.

15. O'Keefe E, Scott-Samuel A. Health impact assessment as an accountability mechanism for the International Monetary Fund: the case of sub-Saharan Africa. Int J Health Serv. 2010;40(2):339-45.

16. Schrecker T, Chapman AR, Labonte R, De Vogli R. Advancing health equity in the global marketplace: how human rights can help. Soc Sci Med. 2010;71(8):1520-6.

17. Stronks K. Generating evidence on interventions to reduce inequalities in health: the Dutch case. Scand J Public Health Suppl. 2002;59:20-5.

18. Scott AJ, Wilson RF. Social determinants of health among African Americans in a rural community in the Deep South: an ecological exploration. Rural Remote Health. 2011;11(1):1634

19. Braveman P. Health disparities and health equity: concepts and measurement. Annu Rev Public Health. 2006;27:167-94.

20. Braveman P. Social conditions, health equity, and human rights. Health Hum Rights. 2010;12(2):31-48.

21. Braveman PA. Monitoring equity in health and healthcare: a conceptual framework. J Health Popul Nutr. 2003;21(3):181-92.

22. Whitehead $M$. The concepts and principles of equity and health. Int J Health Serv. 1992;22(3):429-45.

23. Marmot M. Achieving health equity: from root causes to fair outcomes. Lancet. 2007;370(9593):1153-63.

24. Marmot M, Friel S, Bell R, Houweling TA, Taylor S, Commission on Social Determinants of $\mathrm{H}$. Closing the gap in a generation: health equity through action on the social determinants of health. Lancet. 2008;372(9650):1661-9.

25. Oldenburg B, McGuffog ID, Turrell G. Socioeconomic determinants of health in Australia: policy responses and intervention options. Med J Aust. 2000;172(10):489-92.

26. Oldenburg BF, McGuffog ID, Turrell G. Making a difference to the socioeconomic determinants of health: policy responses and intervention options. Asia Pac J Public Health. 2000;12 Suppl:S51-4.

27. Tajer D. Latin American social medicine: roots, development during the 1990s, and current challenges. Am J Public Health. 2003;93(12):2023-7.

28. Burris S, Anderson ED. A framework convention on global health: social justice lite, or a light on social justice? J Law Med Ethics. 2010;38(3):580-93.

29. Fox AM, Meier BM. Health as freedom: addressing social determinants of global health inequities through the human right to development. Bioethics. 2009;23(2):112-22.

30. Jong-wook L. Global health improvement and WHO: shaping the future. Lancet. 2003;362(9401):2083-8.

31. Jong-wook L. Public health is a social issue. Lancet. 2005;365(9464):1005-6.

32. Costa-Font J, Hernandez-Quevedo C. Measuring inequalities in health: what do we know? What do we need to know? Health Policy. 2012;106(2):195-206.

33. Hanratty B, Burstrom B, Walander A, Whitehead M. Inequality in the face of death? Public expenditure on health care for different socioeconomic groups in the last year of life.J Health Serv Res Policy. 2007;12(2):90-4.
34. Kruk ME, Freedman LP. Assessing health system performance in developing countries: a review of the literature. Health Policy. 2008;85(3):263-76.

35. Ritsatakis A. Equity and the social determinants of health in European cities.J Urban Health. 2013;90 Suppl 1:92-104.

36. Backman G, Hunt P, Khosla R, Jaramillo-Strouss C, Fikre BM, Rumble $C$, et al. Health systems and the right to health: an assessment of 194 countries. Lancet. 2008;372(9655):2047-85.

37. Chopra M, Lawn JE, Sanders D, Barron P, Karim SSA, Bradshaw D, et al. Achieving the health Millennium Development Goals for South Africa: challenges and priorities. Lancet. 2009;374(9694):1023-31.

38. Mayosi BM, Lawn JE, van Niekerk A, Bradshaw D, Abdool Karim SS, Coovadia HM, et al. Health in South Africa: changes and challenges since 2009. Lancet. 2012;380(9858):2029-43.

39. Mogford E, Gould L, Devoght A. Teaching critical health literacy in the US as a means to action on the social determinants of health. Health Promot Int. 2011;26(1):4-13.

40. Solar OAI, World health organization . A conceptual framework for action on the social determinants of health. Social Determinants of Health.Discussion Paper 2 (Policy and Practice). 2010. Available from: http://www.who.int/social_determinants/corner/SDHDP2. pdf.

41. Tashakkori A, Teddlie C. Handbook of mixed methods in social \& behavioral research.United States: Sage; 2003.

42. Jahanshahloo GR, Hosseinzadeh Lotfi F, Izadikhah M. An algorithmic method to extend TOPSIS for decision-making problems with interval data. Appl Math Comput. 2006;175(2):1375-84.

43. Opricovic S, Tzeng GH. Compromise solution by MCDM methods: A comparative analysis of VIKOR and TOPSIS. Eur J Oper Res. 2004;156(2):445-55.

44. Guindon S, Cappeliez P. Contributions of Psychological WellBeing and Social Support to an Integrative Model of Subjective Health in Later Adulthood. Ageing Int. 2010;35(1):38-60.

45. Kaufman L, Karpati A. Understanding the sociocultural roots of childhood obesity: food practices among Latino families of Bushwick, Brooklyn. Soc Sci Med. 2007;64(11):2177-88.

46. Moure-Eraso R, Flum M, Lahiri S, Tilly C, Massawe E. A review of employment conditions as social determinants of health part II: the workplace. New Solut. 2006;16(4):429-48.

47. Muntaner C, Benach J, Chung H, Edwin NG, Schrecker T. Welfare state, labour market inequalities and health. In a global context: an integrated framework. SESPAS report 2010. Gac Sanit. 2010;24 Suppl 1:56-61.

48. Olden K, White SL. Health-related disparities: influence of environmental factors. Med Clin North Am. 2005;89(4):721-38.

49. Siddiqi S, Masud TI, Nishtar S, Peters DH, Sabri B, Bile KM, et al. Framework for assessing governance of the health system in developing countries: gateway to good governance. Health Policy. 2009;90(1):13-25.

50. Thompson-Robinson M, Reininger B, Sellers DB, Saunders R, King D, Ureda J. Conceptual framework for the provision of culturally competent services in public health settings.J Cult Divers. 2006;13(2):97-104.

51. Wasunna AA. 1.20 - Health Demands in Developing Countries. In Taylor JB, Triggle DJ editors. Comprehensive Medicinal Chemistry II. Oxford: Elsevier; 2007. pp. 637-53.

52. Bahadori M, Shams L, Sadeghifar J, Hamouzadeh P, Nejati M. Classification of health structural indicators using scalogram model in golestan province, northern iran. Iran J Public Health. 2012;41(5):58-65.

53. Kassani A, Gohari M, Mousavi M, Asadi Lari M, Rohani M, Shoja M. Determinants of Social Capital in Tehran Residents Using Path Analysis: Urban HEART Study. Iran J Epidemiol. 2012;8(2):1-2.

54. Irwin A, Valentine $\mathrm{N}$, Brown $\mathrm{C}$, Loewenson $\mathrm{R}$, Solar $\mathrm{O}$, Brown $\mathrm{H}$, et al. The commission on social determinants of health: tackling the social roots of health inequities. PLoS Med. 2006;3(6). 